Thoraxdrainagen

DOI 10.1007/978-3-662-49740-1

ERRATUM

\title{
Erratum zu: Thoraxdrainagen
}

\section{Thomas Kiefer Hrsg.}

(c) Springer-Verlag Berlin Heidelberg 2016

Trotz sorgfältiger Erstellung unserer Bücher lassen sich Fehler nie ganz vermeiden.

Daher möchten wir auf Folgendes hinweisen:

Das Autorenverzeichnis wurde nachträglich in die Titelei eingefügt. 